\title{
Idoxuridine in Herpes Zoster: Further Evaluation of Intermittent Topical Therapy
}

\author{
RODNEY DAWBER
}

British Medical fournal, 1974, 2, 526-527

\begin{abstract}
Summary
In a randomized double-blind controlled trial of the value of intermittent topical idoxuridine in treating herpes zoster in 118 patients idoxuridine $5 \%$ in $100 \%$ dimethyl sulphoxide (DMSO), applied four-hourly for four days, significantly shortened the vesicular phase, healing time, and duration of pain; idoxuridine $25 \%$ applied two-hourly produced no greater benefit. The only side effects were transient tender erythema in three patients and "urticarial" oedema in two patients with dermographia.
\end{abstract}

\section{Introduction}

Idoxuridine was first shown to be active against varicellazoster virus in 1964 (Rapp and Vanderslice, 1964). Subsequently Juel-Jensen et al. (1970) confirmed its clinical value of idoxuridine in a double-blind controlled trial showing that $5 \%$ idoxuridine in $100 \%$ dimethyl sulphoxide (DMSO)-a powerful solvent-shortened the healing time and also the duration of postherpetic pain. In view of this and also of the considerable, often protracted, morbidity of zoster it seems surprising that idoxuridine has not been prescribed more often. This has largely been due to controversy over the optimum concentration, frequency, and duration of idoxuridine application; its high cost, which is directly related to the concentration; and fear of toxicity from absorption in view of the toxicity of idoxuridine when given systemically (Silk and Roome, 1970; Juel-Jensen and MacCallum, 1972). Less than $5 \%$ idoxuridine is of little clinical benefit in zoster, and there are no reponted double-blind controlled trials to show unequivocally whether the optimum concentration should be greater for routine clinical practice.

This double-blind controlled trial was carried out to assess further the efficacy of intermittent topical treatment with $5 \%$ idoxuridine in $100 \%$ DMSO (using $100 \%$ DMSO as control) and the toxicity of the treatment.

\section{Patients and Methods}

General practitioners in the hospital's catchment area were asked to refer patients with zoster to hospital, excluding children under 12 years and pregnant women, those in whom the eruption had been present for more than six days, patients with serious associated diseases-for example, neoplasiaand those taking systemic corticosteroids and cytotoxic or immunosuppressive therapy.

After examination patients were referred to the hospital pharmacy, where treatment was allocated according to a series of random numbers. Each patient was supplied with $10 \mathrm{ml}$ of solution in a bottle with a brush in the screw top. Careful instructions were given to paint all the affected areas at twohourly or four-hourly intervals for four days and no other

North Stafiordshire Hospital Centre, Stoke-on-Trent ST4 7PA RODNEY DAWBER, M.B., M.R.C.P., Consultant Dermatologist treatment was applied during this time. Thus each patient received one of six treatments: (a) 100\% DMSO* two-hourly, (b) $100 \%$ DMSO* four-hourly, (c) $5 \%$ idoxuridine in $100 \%$ DMSO* two-hourly, (d) $5 \%$ idoxuridine in $100 \% \mathrm{DMSO}^{*}$ four-hourly, (e) $25 \%$ idoxuridine in $100 \%$ DMSO* two-

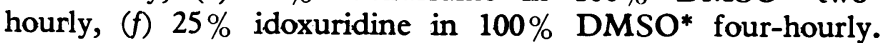

A total of 126 patients were included in the trial. On the first and subsequent weekly attendances blood was taken for haemoglobin, W.B.C. and differential count, platelet count, liver function tests, and blood urea. Both patients and relatives were instructed to note the time of disappearance of vesicles and pain. Those in whom pain was still present at the time of discharge (eight patients) were asked to note when it went.

\section{Results}

Of the 126 patients 118 completed the trial. Eight were lost to follow-up, one of whom died from cerebral thrombosis one day after treatment began. Both $5 \%$ and $25 \%$ idoxuridine significantly shortened the period of vesiculation, healing time (all crusts dropped off), and the duration of pain $(P<0.005$ in each case) (table). There was no significant difference $(a)$ between two- and four-hourly application of idoxuridine and (b) between the $5 \%$ and $25 \%$ idoxuridine $(P>0.05$ in each case).

Results of Treatment of Zoster with Idoxuridine (Results are \pm S.E.)

\begin{tabular}{|c|c|c|c|c|}
\hline $\begin{array}{c}\text { Treatment } \\
\text { (Duration } 4 \text { Days) }\end{array}$ & $\begin{array}{l}\text { No. of } \\
\text { Patients }\end{array}$ & $\begin{array}{l}\text { No. of } \\
\text { Days After } \\
\text { Onset of } \\
\text { Eruption } \\
\text { When } \\
\text { Vesiculation } \\
\text { Stopped }\end{array}$ & $\begin{array}{c}\text { No. of } \\
\text { Days After } \\
\text { Onset of } \\
\text { Eruption } \\
\text { When } \\
\text { All Crusts } \\
\text { Dropped Off }\end{array}$ & $\begin{array}{l}\text { Duration of } \\
\text { Pain (Days) }\end{array}$ \\
\hline $\begin{array}{l}100 \% \text { DMSO 4-hourly } \\
100 \% \text { DMSO 2-hourly } \\
5 \% \text { Idoxuridine in } \\
100 \% \text { DMSO } \\
\text { 4-hourly } \\
5 \% \text { Idoxuridine in } \\
100 \% \text { DMSO } \\
\text { 2-hourly } \\
25 \% \text { Idoxuridine in } \\
100 \% \text { DMSO } \\
\text { 4-hourly } \\
25 \% \text { Idoxuridine in } \\
100 \% \text { DMSO } \\
\text { 2-hourly }\end{array}$ & $\begin{array}{l}20 \\
19 \\
19 \\
20 \\
19 \\
21\end{array}$ & $\begin{array}{l}8.3 \pm 0.4 \\
8.5 \pm 0.35 \\
6.4 \pm 0.15 \\
6.2 \pm 0.3 \\
6.5 \pm 0.2 \\
6.1 \pm 0.3\end{array}$ & $\begin{array}{l}25.4 \pm 1.0 \\
26.8 \pm 1.2 \\
18.3 \pm 0.8 \\
17.6 \pm 0.7 \\
18.8 \pm 0.65 \\
17.9 \pm 0.76\end{array}$ & $\begin{array}{l}19.1 \pm 0.8 \\
19.5 \pm 1.0 \\
9.8 \pm 0.4 \\
9.4 \pm 0.5 \\
9.2 \pm 0.5 \\
9.65 \pm 0.6\end{array}$ \\
\hline
\end{tabular}

Seventeen patients complained of a garlic-like taste due to the therapy but they all completed the treatment. Three patients developed tender erythema in the treated area, two on the third, and one on the fourth day of treatment; two had applied $100 \%$ DMSO every two hours and one $25 \%$ idoxuridine in $100 \%$ DMSO every two hours. The tender erythema remitted within hours of the end of treatment. Two patients with dermographia developed prominent localized areas of weals after the first, second, and third applications. Subsequent treatment was associated only with small, sparse, urticaria-like lesions.

Closed-patch testing was done on five normal subjects with (a) $5 \%$ idoxuridine in white paraffin, (b) $5 \%$ idoxuridine in $100 \%$ DMSO, (c) $100 \%$ DMSO, and (d) $10 \%$ DMSO in normal saline. All the results of tests in groups $(b)$ and $(c)$ were positive at 48 hours and those in groups $(a)$ and $(d)$ were negative. None of the tested areas itched unduly and all resolved 
within 24 hours of removing the patch. No abnormalities of haemoglobin, W.B.C., platelet count, liver function, or blood urea were found during the course of the treatment.

\section{Discussion}

The results showed that intermittently applied $5 \%$ idoxuridine in $100 \%$ DMSO had a considerable effect on zoster (equal to that of $25 \%$ idoxuridine), both in shortening the healing time and in reducing the duration of zoster neuralgia. These results broadly agree with those of others (Juel-Jensen et al., 1970). Juel-Jensen and MacCallum (1972) funther suggested, however, that $40 \%$ idoxuridine in $100 \%$ DMSO, applied continuously on a dressing, gives even greater benefit. In view of the great expense of continuous application-up to $£ 60$ per patient (Juel-Jensen, 1973)-the good results from intermittent $5 \%$ idoxuridine application as described here, and the failure of $25 \%$ idoxuridine to give any greater benefit $5 \%$ idoxuridine in $100 \%$ DMSO applied four-hourly is probably satisfactory for noutine use. Idoxuridine $40 \%$ in $100 \%$ DMSO should be used only in the treatment of severe cases, under hospital supervision.

Systemic idoxuridine is potentially very toxic, panticularly to the bone marrow, and should therefore be reserved for lifethreatening conditions such as herpes simplex encephalitis. No systemic abnormalities have yet been described after therapy with topical idoxuridine in DMSO. None of our 118 patients developed any ovent signs of haematological, hepatic, or renal toxicity; the design of the trial did leave open the possibility of transient impairment of these organs during the early stages of treatment. Nevertheless, the absence of symptoms and signs of toxicity during this period, the subsequent normal results of investigations, and the absence of reported side effects all show the application to be safe. Since idoxuridine interferes with DNA synthesis and cell division it is on no account to be recommended for pregnant women, and it cannot be recommended for children until results of its use in them have been studied.

The patch tests showed that DMSO is a primary irritant, which probably explains the reponts of maceration of skin (Juel-Jensen and MacCallum, 1972), and even full-thickness skin loss (Dawber, 1973), after treatment with high concentrations of DMSO, which were applied very often for many days. Because treatment was intermittent only slight tender erythma occurred in a few patients in this study.

I should like to thank WB Pharmaceuticals Ltd, Fulton House, Empire Way, Wembley, for help with part of the trial and for supplying much of the idoxuridine and Julia Massey, systems analyst at North Staffordshire Hospital Centre, for invaluable statistical help.

\section{References}

Dawber, R. P. R. (1973). British Medical fournal, 1, 737

Juel-Jensen, B. E., MacCallum, F. O., Mackenzie, A. M. R., and Pike, M. G. (1970). British Medical fournal, 4, 776.

Juel-Jensen, B. E., and MacCallum, F. O. (1972). Herpes Simplex, Varicella and Zoster, p. 154. London, Heinemann.

Juel-Jensen, B. E. (1973). British Medical fournal, 1, 406.

Rapp, F., and Vanderslice, D. (1964). Virology, 22, 321.

Silk, B. R., and Roome, A. P. G. (1970). Lancet, 1, 411

\title{
Serum $\alpha$-Fetoprotein: Diagnostic Significance in Liver Disease
}

\author{
ERKKI RUOSLAHTI, MIKKO SALASPURO, HELENA PIHKO, LEIF ANDERSSON, \\ MARKKU SEPPÄLÄ
}

British Medical fournal, 1974, 2, 527-529

\section{Summary}

Raised serum $\alpha$-fetoprotein levels measured by radioimmunoassay were found in 19 out of $24(79 \%)$ patients with primary liver cancer and in 32 out of $311(10 \%)$ patients with other liver diseases. The rise was transient in cases of hepatitis and a transient rise was also seen after alcohol intake ceased in two patients with cirrhosis.

Department of Serology and Bacteriology, University of Helsinki, Finland

ERKKI RUOSLAHTI, M.D., Senior Lecturer in Immunology

HELENA PIHKO, M.D., Research Assistant

Department II of Medicine, University Central Hospital, Helsinki, Finland

MIKKO SALASPURO, M.D., Senior Physician

Department III of Pathology, University of Helsinki, Helsinki, Finland

LEIF C. ANDERSSON, M.D., Lecturer in Pathology

Department II of Obstetrics and Gynaecology, University Central Hospital, Helsinki, Finland

MARKKU SEPPÄLÄ, M.D., Senior Lecturer in Obstetrics and Gynaecology
$\alpha$-Fetoprotein levels exceeding $500 \mathrm{ng} / \mathrm{ml}$ were 30-50 times more common in primary liver cancer than in other liver diseases. A rise in level seems to reflect the extent of liver regeneration in liver diseases other than primary cancer.

\section{Introduction}

Primary liver cancer and teratocarcinomas are often associated with high circulating $\alpha$-fetoprotein levels. Concentrations down to normal (1-16 $\mathrm{ng} / \mathrm{ml})$ can be measured by radioimmunoassay (Ruoslahti and Seppälä, 1971; Chayvialle and Ganguli, 1973). Because of its sensitivity this method is of value not only in the diagnosis of primary liver cancer but also in detecting small rises in $\alpha$-fetoprotein level sometimes associated with other liver diseases, such as secondary liver cancer, hepatitis, and cirrhosis, with trauma, and with pregnancy (Elgort et al., 1972; Ruoslahti and Seppälä, 1972; Seppälä and Ruoslahti, 1972; Ruoslahti et al., 1972, 1973; Nishi and Hirai, 1973). The pathophysiology and the diagnostic significance of raised $\alpha$-fetoprotein levels in these conditions are not fully understood.

We have been using the radioimmunoassay test for $\alpha$ fetoprotein routinely for two years. We can now estimate the significance of various levels in the diagnosis of primary liver 